\title{
O DISCURSO CIENTÍFICO NA ENUNCIAÇÃO TERAPÊUTICO-MIDIÁTICA: AUGUSTO CURY E 0 TEATRO DAS MENTES ${ }^{1}$
}

\author{
Anderson FERREIRA²
}

\section{CONSIDERAÇÕES INICIAIS}

Este capítulo tem por escopo examinar os atravessamentos do discurso científico na enunciação terapêutica de canais da rede social You Tube. Objetivamos verificar um "fio condutor discursivo" - uma unidade temática "apagada"; um "efeito de sentido social" - um objeto opaco percebido como um certo "mal-estar social", o qual recorta tanto discursos científicos, como discursos "mais abertos" das mídias.

Como corpus de apoio, selecionamos discursos científicos cujos enunciados gravitam em torno da formação discursiva temática "sociedade contemporânea". Em geral, esses discursos acomodam diferentes posicionamentos, e, por consequência, diversos "tons". Mas os que nos interessam enunciam acerca de certo pessimismo quanto ao estado atual da sociedade ocidental contemporânea, por meio de um "tom" que vivifica um mal-estar social difuso; o qual Sigmund Freud identificou já no início do século XX, em seus escritos culturais. Como corpus de referência, destacamos o discurso de três vídeos na rede social You Tube, assumidos pelo nome de autor Augusto Cury. ${ }^{3}$

Nossa hipótese é que a enunciação terapêutico-midiática no corpus de referência, na medida em que recorre ao discurso científico para se legitimar, procede de maneira duplamente redutora: i) procura "formar" formações discursivas "pessimistas" acerca da atual sociedade (sociedade doente, sociedade estressante etc.), ao mesmo tempo em que; ii) instaura, em seu interior, um $e u$, que, descar-

1 O presente trabalho foi realizado com apoio da Coordenação de Aperfeiçoamento de Pessoal de Nível Superior - Brasil (CAPES/PNPD) - Número do Processo: 88887.363124/2019-00

2 E-mail: andersonferreirasp94@gmail.com

3 Augusto Cury é médico psiquiatra, psicoterapeuta, pesquisador e escritor brasileiro. 
tando a mesma sociedade, torna-se objeto de sintomas e diagnósticos num espaço discursivo de cura. Assim, o eu inscreve um sujeito que incorpora técnicas neoliberais para se livrar das angústias e sofrimentos que, muitas vezes, surgiram no elã do comportamento neoliberal. Mobilizando vernizes do discurso científico em detrimento do poder da psiquiatria, a enunciação terapêutico-midiática procura se legitimar como a panaceia dos sofrimentos psicossociais.

Não podemos enfatizar, contudo, que a prática da terapia em canais do You Tube seja uma proposta ilegítima, uma vez que, em muitos casos, é um especialista quem fala. Nikolas Rose (2020, on-line) afirma que o papel da psiquiatria não é limitado a apenas identificar e tratar pessoas com transtornos mentais, mas a ocupar o espaço informacional, instrutivo e didático que ensina as pessoas a administrar e melhorar a saúde da mente. Rose completa:

Temos também um número crescente de aplicativos móveis e sites na internet onde as pessoas auto-diagnosticam seus problemas psiquiátricos e são ensinadas a fazer uso de vários tipos de técnicas diferentes, como tipos de terapia cognitivo-comportamental ou versões da meditação ao estilo do mindfulness [usada frequentemente em empresas para aliviar o estresse] e assim por diante, para administrar sua angústia em sua vida cotidiana (ROSE, 2020, on-line).

Sem querer especular sobre a eficácia desses métodos, visamos a examinar os atravessamentos do discurso científico na enunciação terapêutico-midiática, materializada na internet. Este capítulo, então, está dividido da seguinte forma:

- Na seção, A enunciação terapêutica, discutimos acerca da irradiação da terapia nos espaços sociais e digitais, considerando que a prática da terapia, ou o seu sucesso nas redes de comunicação, deve-se às condições sócio-históricas e culturais da sociedade contemporânea.

- Na seção, O mal-estar nas sociedades ocidentalizadas, visamos a apresentar, de modo suscinto, uma perspectiva, em particular das ciências humanas e sociais, que considera as fissuras psicossociais das sociedades contemporâneas como constitutivas da intersubjetividade. Trata-se de aventar que o objeto opaco, "o mal-estar social", atravessa o discurso das ciências contemporâneas.

- Na seção, O discurso científico, apresentamos os pressupostos teóricos-metodológicos da noção de discurso constituinte, postulada por Maingueneau e Cossuta (1995) e Maingueneau (2000, 2006, 2008, entre outros).

- Na seção, O efeito de mal-estar social no discurso científico: um 
corpus de apoio, apresentamos recortes dos discursos das ciências sociais e humanos acerca das condições sócio-históricas atuais.

- Na seção, A enunciação terapêutico-midiática: um corpus de referência, procederemos as análises dos textos selecionados, tomando-os como discurso.

\section{A ENUNCIAÇÃO TERAPÊUTICA}

A terapia pode ser compreendida, grosso modo, como um conjunto de práticas que agrupa finalidades específicas, na medida em que objetivam auxiliar o indivíduo a refletir e a identificar possíveis gêneses de sofrimentos, para, a partir daí, estabelecer maneiras de superá-los. Nesse sentido, o objetivo da terapia não é curar uma suposta doença, mas promover o autoconhecimento. De forma que uma enunciação terapêutica não está centrada apenas no polo do enunciador, já que a terapia se constitui no diálogo, considerando a diversidade de cada indivíduo. Nessa ótica, seria mais justo nomeá-la de co-enunciação terapêutica, no sentido de uma "acentuação da relação discursiva com o parceiro [...]" (BENVENISTE, 1970/2006, p. 87), ou mesmo, de "uma acomodação intersubjetiva" (CULIOLI, 1973, p. 87 apud MAINGUENEAU e CHARAUDEAU, 2008, p. 194).

A partir dessa visão geral, é possível tomar a prática terapêutica por muitos pontos de intersecção. Queremos destacar, contudo, a prática terapêutica vinculada à psiquiatria e à psicoterapia, em particular, aquela que recebe as pessoas que experimentam o que consideram "transtornos mentais" (ROSE, on-line, 2020). Existe uma tendência - criticada pela comunidade médica - de os usuários da internet se autodiagnosticaram por meio de checagens em sites, blogs e canais de informação sobre saúde. No que se refere à prática terapêutica e psicoterapêutica, a prática do autodiagnóstico também é comum.

Em geral, no âmbito da internet, os sujeitos-produtores de conteúdos médico-terapêuticos se limitam a informar, já que o exercício da prática médica é considerado ilegal. ${ }^{4}$ Assim, a enunciação terapêutica mobiliza ações performativas (ordens, advertências, promessas, garantias). Conforme observarmos na "neurastenia", descoberta e forjada por George Miller Beard (1839-1883), e na depressão, estudada por Junko Kitanaka (1970), no Japão, as prescrições, nestes

4 O exercício ilegal da medicina é crime, tipificado no art. 282 do Código Penal (CP), punível com detenção de até dois anos por quem o pratica, além de multa. 
casos, eram descansar e ensinar métodos de gerenciar o estresse, o equilíbrio emocional e o profissional, como nos informa Rose (on-line, 2020). Mas isso mudou, pois

[...] desde o início dos anos 1990, você vê uma dupla emergência. Por um lado, esse modo tradicional de pensar sobre o mal-estar do corpo e da alma é substituído pelo diagnóstico de depressão. Por outro, vemos a introdução do Prozac e medicamentos similares para o tratamento da depressão.

Com a produção de inúmeros canais de co-comunicação, presenciamos, outrossim, a busca por diagnósticos, métodos e medicamentos controlados na rede. Esse fenômeno é revelador, pois evidencia, na prática dos usuários da rede mundial, aquilo que as pesquisas em torno da temática "sociedade contemporânea" têm mostrado sobre a mobilidade social e psíquica dos sujeitos, para os quais o efeito de "mal-estar social" é centrípeto, pois se move em direção ao centro dos espaços de convivência, inclusive, aqueles que não são afetados diretamente pela aceleração e normatização dos modos de vida sócio-urbanos.

A enunciação terapêutica, então, pode ser tomada no bojo das práticas verbais que enunciam sobre a ansiedade e a depressão, por exemplo. ${ }^{5}$ Nesse ponto é que se imbricam as condições sócio-históricas e culturais da sociedade contemporânea e certa sensação de "mal-estar" percebida pelos sujeitos. A enunciação terapêutica atravessa, então, não somente discursos que se irradiam como instrumentos de motivação para iluminar a positividade da vida, mas também discursos científicos no interior dos quais a positividade é, muitas vezes, implodida. De fato, as condições de enunciabilidade da enunciação terapêutica são constitutivas do mal-estar social na vida contemporânea. É, portanto, a respeito desse efeito de "mal-estar" nas sociedades ocidentalizadas que passamos a falar.

\section{O MAL-ESTAR NAS SOCIEDADES OCIDENTALIZADAS}

Nas sociedades contemporâneas, a vida tem sido percebida sob o signo da mudança e do movimento. O tempo e o espaço exercem um papel preponderante na mobilidade social e cultural dos sujeitos. As tecnologias instituíram novos espaços de mobilidade e sequestraram parte do tempo de vida, ao passo que a solidão e o medo instauraram uma sensação de mal-estar. A comunicação entre os sujeitos aumentou consideravelmente, embora a relação entre os corpos tenha diminuído. Jameson (1985) descreve a mobilidade dos sujeitos contemporâneos

5 Doenças psiquiátricas consideradas graves. 
como um comportamento esquizofrênico já que, despossuídos de identidade pessoal, os sujeitos engendrariam uma relação a-histórica com o tempo. Trata-se de uma metáfora da vida como presente perpétuo e como ação do exagero. Na mesma linha, Lipovetsky (2004) argumenta que a sociedade contemporânea, se tomada num conjunto, pode ser percebida pelo comportamento esquizofrênico entre o exagero e o equilíbrio.

O efeito de mal-estar, contudo, não tem sido produzido apenas pela racionalização da vida pós-moderna. Ele resulta, em muitos casos, de um posicionamento crítico em oposição a um pensamento apassivador; bem como de uma imersão íntimo-psíquica do sujeito "pós-moderno" em detrimento da prática de consumo (BAUDRILLARD, 1970) e da exacerbação do espetáculo (DEBORD, 1997). Nesse quadro, o discurso científico tem descoberto diversas rupturas psicossociais no último meio século.

$\mathrm{Na}$ verdade, o discurso científico, na medida em que tematiza o contemporâneo, ilumina uma sociedade porosa que não se deixa ver em toda a sua heterogeneidade; fissuras sociais, políticas e culturais. Nos espaços da fixidez, do sempiterno e da compacidade, verificou-se a mobilidade, o efêmero e a liquidez. Abandonou-se, assim, os dualismos, já que as repartições estanques se rareavam nas fronteiras da simultaneidade e da transfiguração. O efeito de mal-estar, portanto, pôde ser apreendido, no discurso das ciências contemporâneas, pela sensação de estar sempre derrapando.

Não que o discurso científico do último século deixou de propor alternativas. Basta observar as primeiras palavras de Santos (2000, p. 7), no que respeita à atitude científica:

Este livro quer ser uma reflexão independente sobre o nosso tempo, um pensamento sobre os seus fundamentos materiais e políticos, uma vontade de explicar os problemas e dores do mundo atual. Mas, apesar das dificuldades da era presente, quer também ser uma mensagem portadora de razões objetivas para prosseguir vivendo e lutando.

O efeito de mal-estar se produz nas fissuras existentes do discurso de Santos (2000) que enuncia "os problemas e as dores do mundo atual”, mas mobiliza a razão objetiva a fim de viver, lutar e prosseguir. De forma geral, as ciências - em particular, a ciências sociais e humanas - têm percorrido os caminhos em busca do diálogo e da compreensão. Contudo, o próprio gesto de propor alternativas faz das ciências humanas e sociais, sobretudo na América Latina, um discurso do devir, embora tente se autolegitimar fundando as estruturas que represarão as cisões sociais, econômicas, políticas e culturais que se alargam cada vez mais. Eis que chegamos aos pressupostos teóricos-metodológicos da noção de discurso 
constituinte, postulada por Maingueneau e Cossuta (1995) e Maingueneau (2000, 2006, 2008, entre outros).

\section{OS DISCURSOS CONSTITUINTES: EM FOCO DISCURSO CIENTÍFICO ${ }^{6}$}

O discurso científico - assim como os demais discursos constituintes ${ }^{7}$ (MAINGUENEAU e COSSUTA, 1995; MAINGUENEAU, 2000, 2006, 2008) - procura apagar a ideia de restrição de leitura do mundo, haja vista que eles são mobilizados pelos sujeitos para interpretar, explicar e solucionar os problemas de uma dada sociedade. De fato, "os discursos constituintes pretendem delimitar [...] o lugar-comum da coletividade, o espaço que engloba a infinidade de 'lugares-comuns que aí circulam'" (MAINGUENEAU, 2008, p. 39). Com isso, a enunciação científica produz um efeito de sentido de totalidade, de fechamento dos posicionamentos e, em última instância, de verdade.

Maingueneau e Cossuta (1995) e Maingueneau (2000, 2006, 2008) afirmam - quando observam a existência de um continuum entre discurso constituintes e não-constituintes, bem como entre os discursos constituintes entre si que a pretensão dos discursos constituintes é fundar e não ser fundados. Nesse sentido, outros discursos os atravessam e são por eles atravessados. É possível conjecturar esses atravessamentos entre o discurso científico e os discursos do mundo plebeu das mídias, para usar o termo de Bourdieu (1998).

No campo midiático (e não apenas) o discurso científico não se deixa apreender em toda sua extensão. Para evocar para si uma autoridade fundante, seus enunciadores investem, muitas vezes, em "falas" coladas à Ciência, evocando instituições legítimas, enunciadores consagrados, lugares e papéis sociais e memórias, de forma a garantir e validar gêneros de discursos não-constituintes que circulam naquele mundo plebeu.

Diríamos, então, que, nesses casos, não estamos mais tratando de discurso científico propriamente dito - para o qual seria necessário se comunicar com uma comunidade reduzida -, mas com discursos não-constituintes, aos quais o discurso científico atravessa e submete. Se nos discursos constituintes os enunciadores

6 Estamos tomando o discurso científico neste texto como uma intricação entre a Ciência e a instituição acadêmica universitária sem aprofundar as suas práticas concretas de comunicação, bem como seus parceiros legítimos. Para ampliar o assunto, recomendamos o texto da professora Maria Aldina Marques, neste livro. Marques propõe uma distinção "possível e necessária” entre discurso científico e discurso acadêmico.

7 Para Maingueneau (2000, 2006, 2008b), o religioso, o filosófico, o científico e o literário. 
se colocam "de acordo com as normas internas de um grupo e não com a doxa universalmente partilhada" (MAINGUENEAU, 2008b); nos discursos que circulam nas mídias é, muitas vezes, a doxa universal que é validada positivamente. Nesse ponto, é conveniente verificar os atravessamentos estratégicos entre os discursos constituintes e não-constituintes. Em última instância, apreender, no efeito de atravessamento, certa didatização, midiatização e digitalização do archéion (MAINGUENEAU, 2000, 2006, 2008).

Nessa perspectiva, os modos de produção, circulação, disseminação, coprodução, memorização e arquivamento dos discursos têm relevância nas formas de sedimentação do discurso científico. Com efeito, o advento das tecnologias da informação e da comunicação possibilitou a existência de novos mídiuns (DEBRAY, 1993; MAINGUENEAU, 2006, 2013), os quais têm um papel relevante, pois seu aparecimento incitou novas gestos de produção, leitura e consumo dos discursos em circulação social.

No campo das mídias, os discursos não-constituintes em torno da fórmula "sociedade ocidental", por exemplo (Cf. KRIEG-PLANQUE, 2010), reúne uma quantidade significativa de atravessamentos. Os sujeitos que falam desse lugar mobilizam "discursos últimos para além dos quais não há senão o indizível, de que eles se confrontam com o Absoluto" (MAINGUENEAU, 2000, p. 6). De fato, para dar conta das exigências da sociedade contemporânea, são chamados a intervir o discurso religioso, o literário, o filosófico, o científico..., cada qual tentando submeter o outro a seus próprios princípios.

Os textos colocados em circulação por essas comunidades discursivas carregam um regime textual construído historicamente, ao mesmo tempo em que possibilitam a existência de um grupo de indivíduos que falam através de instituições legitimadas. As noções textualizadas, então, atravessam e penetram os demais discursos em circulação social, tornando-se verdadeiros signos de pertencimento e, muitas vezes, etiquetas discursivas. No que se refere, por exemplo, à compreensão das conjunturas sociais, políticas, culturais e econômicas da sociedade contemporânea, o discurso científico é um instaurador de discursividades, haja vista que se constrói se referindo a si mesmo, a outros discursos constituintes e, também, a outros discursos em circulação social mais aberta.

É por isso que as condições sócio-históricas e culturais das sociedades ocidentalizadas apenas podem ser compreendidas por meio de um sistema de referências de um discurso a outros. Evocando a sua autoridade, o discurso científico se pretende constituinte, com isso, "amarra-se" e é "amarrado", como dissemos, a instituições legitimadas, a enunciadores consagrados, a lugares e papéis sociais e discursivos e a memórias validadas positiva e negativamente, de acordo com o antagonista. 
No bojo do interdiscurso, a constituição do discurso científico pode ser apreendida conforme as dimensões ativa e organizacional. Maingueneau (2008) ressalta que a primeira dimensão visa a estabelecer legalmente, no interior do processo de instauração do discurso, a construção da própria emergência desse discurso. A segunda, a dimensão organizacional, trata de inscrever no discurso uma coesão, para que se construa, materialmente, uma unidade textual "inteira".

Mediante a esse processo de constituição, será preciso observar a maneira pela qual o discurso científico requisita sua legitimação no mundo plebeu nas mídias; ou melhor, de que forma essa legitimação é mobilizada pelo seus enunciadores. Será preciso, então, especificar o que significa dizer "sociedade contemporânea", pois é nela que "fórmulas discursivas" como pós-modernismo, sociedade líquida e sociedade da informação, por exemplo, foram possíveis. E é nela, portanto, que a enunciação terapêutica, na internet, tende a ser midiatizada. Por consequência, é, no campo das mídias, que os atravessamentos mais esparsos entre discursos constituintes e não-constituintes se revelam.

\section{O EFEITO DE MAL-ESTAR SOCIAL NO DISCURSO CIENTÍFICO: UM CORPUS DE APOIO}

Num campo clivado entre o científico e o midiático, um só indivíduo pode estar inserido numa sociedade do consumo (BAUDRILLARD, 1970; JAMESON, 1985), do espetáculo (DEBORD, 1997), da cibercultura (LEVY, 2009); sociedades estas que estariam no interior de uma sociedade industrial (LYOTARD, 1979;), moderna (GIDDENS, 1991), transparente (VATTIMO, 1992), pós-moderna (EAGLEATON, 1996); pós-industrial (KUMAR, 1997), líquida (BAUMAN, 2001), hipermoderna (LIPOVETSKY, 2004), excitada (TÜRCKE, 2010), dentre outras. De fato, a leitura da contemporaneidade é produzida por recortes dimensionais que mobilizam estatutos sociocognitivos, político-econômicos, técnico-culturais, étnico-religiosos etc.

No quadro dessas categorizações de sociedade, os enunciadores do campo científico fundam conceitos mais resistentes; advindos de posicionamentos de identidades enunciativas fortes, como esclarece Maingueneau (2000, p. 8):

As diversas escolas filosóficas do mundo helênico não são as correntes ou escolas de ciências humanas ou os laboratórios da física contemporânea, mas em todos esses casos o posicionamento supõe a existência de grupos mais ou menos institucionalizados, de comunidades discursivas, que não existem senão pela e na enunciação dos textos que elas produzem e fazem circular. O posicionamento não é, portanto, apenas uma doutrina, a articulação de ideias; é a intricação de uma certa configuração textual e de um modo de existência de um conjunto de homens. 
Não obstante isso, é sabido que a compreensão dos modos de funcionamento e organização de uma dada sociedade se oferece de modo parcial. De fato, uma leitura do mundo deveria sempre ser admitida como limitada e insuficiente. Diante da impossibilidade de apreensão de seus elementos discursivo-semióticos, seria preciso considerar a heterogeneidade de vozes que lutam no sentido de apreender, interpretar e explicar - para si e para o outro - o "nosso tempo".

Por esse motivo, o efeito de mal-estar social apenas pode ser apreendido por um recorte interpretativo. Isto é, um gesto de leitura que, num conjunto de textos previamente selecionados, ilumine enunciados em torno de uma formação discursiva temática que o analista instituiu de forma soberana, embora o "tom" de pessimismo social esteja presente em diversos espaços sociais, civis e não-civis, como lembra Bauman (2001).

A fim de tentar desvelar esse "tom”, selecionamos um corpus de apoio que engendra reflexões científicas acerca das conjunturas sociais, políticas, culturais, econômicas e subjetivas das sociedades contemporâneas no século XX e XXI. Trata-se, sem dúvida, de um recorte bem limitado, mas, pelas experiências que temos com esse discursos, pode servir para iluminar aquilo que estamos chamando de efeito de sentido de mal-estar social, que, como esclarecemos no início desta discussão, visa a desvelar um objeto opaco que tange os discursos constituintes e os discursos não-constituintes.

Nosso corpus de apoio foi constituído de quatro discursos científicos e reunidos conforme os seguintes critérios:

[1] Tempo e momento. Discursos enunciados entre século XX e XXI;

[2] Constituência. Discursos ligados às ciências humanas e sociais; e

[3] Posicionamento. Discursos construídos no bojo da comunidade científico-acadêmica.

Vejamos:

$[\mathrm{A}]^{8}$

[...] as atuais condições são francamente desfavoráveis. Paradoxalmente (para não dizer esquizofrenicamente), a sociedade moderna adota, por um lado, uma devoção ao cientificismo, acreditando que a ciência é toda-poderosa e pode criar tecnologias para resolver todos os problemas; por outro lado, essa mesma sociedade defende um forte anti-intelectualismo, ao acreditar que os intelectuais, incluindo os

8 Beaugrande, New foundations for a science of text and discourse: cognition, communication and freedom of access to knowledge and society 1997, $\mathrm{n} / \mathrm{p}$. 
cientistas, são pessoas afetadas e esnobes que usam seus próprios jargões para nos enredar nos seus obscuros trabalhos e teorias ao cuidar dos problemas da sociedade.

$[\mathrm{B}]^{9}$

Na sociedade pós-moderna e de consumo, escolher é o destino de todos, mas os limites de escolhas realistas diferem e também diferem os estoques de recursos necessários para fazê-las. É a responsabilidade individual pela escolha que é igualmente distribuída, não os meios individualmente possuídos para agir de acordo com essa responsabilidade.

$[C]^{10}$

Um dos traços marcantes do atual período histórico é, pois, o papel verdadeiramente despótico da informação. Conforme já vimos, as novas condições técnicas deveriam permitir a ampliação do conhecimento do planeta, dos objetos que o formam, das sociedades que o habitam e dos homens em sua realidade intrínseca. Todavia, nas condições atuais, as técnicas da informação são principalmente utilizadas por um punhado de atores em função de seus objetivos particulares. Essas técnicas da informação (por enquanto) são apropriadas por alguns Estados e por algumas empresas, aprofundando assim os processos de criação de desigualdades. É desse modo que a periferia do sistema capitalista acaba se tornando ainda mais periférica, seja porque não dispõe totalmente dos novos meios de produção, seja porque lhe escapa a possibilidade de controle.

$[\mathrm{D}]^{11}$

A violência competitiva, a ansiedade que essa violência implica, é uma translação de uma ansiedade sexual que é unicamente mascu-

9 Bauman, O mal-estar da pós modernidade 1998, p. 243.

10 Santos, Por uma outra globalização: do pensamento único à consciência universal, 2000, p. 19-20.

${ }^{11}$ Franco Berardi, entrevistado por Juan Íñigo Ibáñez. Tradução: Inês Castilho e Simone Paz, em Outras Palavras, 2017. Disponível em: <https://outraspalavras.net/posts/neoliberalismo-assexualidade-e-desejo-de-morte > Postado em: 27 jan. 2017. Acesso em: 07 fev. 2020. 
lina. As mulheres são vítimas da violência financeira, bem como da vingança masculina e terrorista contra a violência financeira. A cultura feminista pode considerar-se a única forma cultural e existencial que poderia criar lugares psíquicos e físicos de autonomia frente à agressão econômica e à agressão terrorista suicida. Porém, hoje, quando falamos de suicídio, cabe ressaltar que não estamos falando do velho suicídio romântico, que significava um desespero amoroso, uma tentativa de vingança de amor, um excesso de pulsão erótica. Falamos de um suicídio frio, de uma tentativa de fugir da depressão e da frustração.

O discurso em [A] pode ser encontrado da introdução do livro New foundations for a science of text and discourse: cognition, communication and freedom of access to knowledge and societ, do linguista norte-americano Robert-Alain de Beaugrande (1946-2008). Como acresenta em nota a tradutora Maria Inez Matoso Silveira, nas condições sócio-históricas e políticas do Brasil, a proposta defendida no referido livro deve ser melhor traduzida como "promover o acesso ao conhecimento e à cidadania através do discurso". Nesse sentido, fez-se necessário, na enunciação científica do discurso em [A], iluminar as atuais condições sócio-históricas da contemporaneidade.

O discurso em [B], do sociólogo polonês Zygmunt Bauman (1925-2017), faz parte daquilo que seus comentadores chamam de fio condutor que conduz a escrita de Bauman, isto é, certo incômodo acerca da vida moderna, que mais tarde este autor traduziu como liquidez das inter-relações sociais e humanas. De fato, Bauman, na maioria de suas obras, elabora uma morfologia social das condições atuais da vida na sociedade ocidental contemporânea, ressaltando a ideia de liquidez e efemeridade.

O discurso em [C] remete à obra de final de vida do geógrafo brasileiro Milton Santos (1926-2001), que faz uma leitura social e política das condições sócio-históricas da sociedade brasileira e da América Latina no final do século XX, em particular, em relação às formas de ocidentalização desses locais. A essa imposição pela técnica e pelo capital, o autor chama de globalitarismo.

Por último, o discurso em [D] diz respeito a uma entrevista dada pelo filósofo italiano Franco Berardi (1946) à revista on-line Outras Palavras, em 2017. Berardi aponta que a obsessão pelo sucesso individual e a troca dos contatos corpóreos pelos contatos digitais podem realizar uma distopia da humanidade insensível. Segundo o filósofo, a questão política é fundamental para compreendermos os sofrimentos e angústias contemporâneos, já que, diz ele, “o neoliberalismo - mais a mediatização das relações sociais - produziu um efeito de fragili- 
zação psíquica e de agressividade econômica claramente perigosa e no limite do suicídio" (BERARDI, on-line, 2017).

Quando reunido, esse conjunto de textos pode ser ligado por um fio condutor discursivo que estamos chamando de efeito de mal-estar social. $\mathrm{Na}$ verdade, cada discurso acima procura se tornar uma leitura decisiva da sociedade contemporânea. O efeito de mal-estar social, então, irradia certo desalento a respeito das atuais condições sócio-históricas e culturais e, por conseguinte, propaga-se nos espaços sociais de convivência. Não é a posição de "toda” Ciência, mas está legitimado por ela. E, de outra forma, o efeito de mal-estar social não atinge a totalidade dos indivíduos. Mas, no espaço digital, esse efeito tende a conduzir o sujeito a uma condição de individualização competitiva e de isolamento psíquico. Nesse cenário, as práticas de terapia digital são abundantes.

\section{A ENUNCIAÇÃO TERAPÊUTICO-MIDIÁTICA: UM CORPUS DE REFERÊNCIA ${ }^{12}$}

Antes de iniciarmos as análises, cabe lembrar dos critérios de escolha dos três discursos a seguir, materializados nos textos [1], [2] e [3].

[1] Abrangência. Os discursos em torno do nome de autor Augusto Cury estão associados a livros, sites, palestras, aulas, vídeos, dentro e fora do país.

[2] Clivagem. Os discursos em torno do nome de autor Augusto Cury estão associados ao papel social de psiquiatra, cientista, escritor, palestrante e educador, operando, assim, uma clivagem no campo ciência-médica, da literatura, da educação e das mídias. ${ }^{13}$

[3] Modos de dizer. Os discursos selecionados recorrem a uma enunciação motivacional-religiosa. Trata-se de vídeos introdutórios que visam a evocar uma espécie de proteção do eu, construindo uma encenação estoicista no teatro das mentes.

As numerações visam a facilitar as citações nas análises.

12 Como nosso objetivo principal é examinar os atravessamentos do discurso científico na enunciação que chamamos de terapêutica, focalizamos a linguagem verbal, aceitando que essa escolha limita a produção dos efeitos de sentido, já que se tratava de um texto multissemiótico. .

13 Disponível em: <https://augustocury.com.br/> Acesso em: 15 fev. 2020. 
Texto $[1]^{14}$

[\$1] As emoções nascem muito antes do primeiro suspiro existencial. Nascem na ansiedade da espera, nos acompanham na frustração dos primeiros passos, no aconchego de um abraço, no medo do primeiro dia de aula, na tristeza da derrota.

[\$2] Está na nota 10, inclusive, na indecisão da escolba profissional, no medo de falhar, nas exigências do mercado de trabalho; está no primeiro beijo, nas rejeições. Está quando você sente a pulsação de que é um ser humano único e irrepetivel.

[\$3] Se as emoções nos acompanham em toda nossa vida, como negá-las? Como ignorá-las? Desprezá-las? Nós precisamos aprender as ferramentas mais importantes para geri-la.

[\$4] Quantas vezes você já se perguntou: Por que eu fui fazer isso? Por que não tive autocontrole? Quantas vezes eu magoei pessoas que me são tão caras? Quantas vezes eu repeti erros que já tinha jurado que não ia mais cometê-los?

[\$5] Superar a baixa autoestima é muito importante. Reciclar nossas mágoas, autopunição, autocobrança, complexos de inferioridade, medos. Quantos medos assaltam a nossa mente? Porque infelizmente as pessoas se preocupam em ter amizade com os outros mais não amizade consigo. Se preocupam em ter uma romance com uma outra pessoa, mas se esquecem que, se elas não aprenderem a ter um romance com a sua própria história, com a sua saúde emocional, com a sua liberdade, criatividade e capacidade de gerir a sua emoção, elas poderão ser escravas vivendo em sociedades democráticas.

[\$6] Por que você não tem autocontrole em alguns momentos? Por que perde a paciência? Por que não gere seus pensamentos? Por que não protege a sua emoção? Por que reage impulsivamente? E por que, muitas vezes, você tem a sensação de que não dirige o seu próprio script?

[\$77] Muitas vezes, não temos problemas no teatro social - fora de nós - mas criamos problemas no teatro da nossa mente. Não se preocupe se você sente que, em muitos momentos, o pior inimigo seu é você mesmo.

14 Gestão da Emoção. Disponível em: <https://www.youtube.com/watch?v=4A_8BSAJdDw>. Acesso em: 12 fev. 2020. 
[\$8] Muitas pessoas podem nos ferir, nos magoar, nos rejeitar, nos criticar, mas ninguém pode asfixiar tanto a sua saúde emocional, a sua criatividade, a sua liberdade do que você mesmo, do que nós mesmos.

Em $[\$ 1]$, [ 2 ], o que o enunciador chama de "emoções" podemos chamar de relações socioculturais: "ansiedade da espera, frustração dos primeiros passos, aconchego de um abraço, medo do primeiro dia de aula, tristeza da derrota"; de relações socioinstitucionais: "a nota 10 , a indecisão da escolha profissional, o medo de falhar, as exigências do mercado de trabalho". E, finalmente, de relações psicossociais: "o primeiro beijo, as rejeições [...] a pulsação de que é um ser humano único e irrepetível”. Mas reduzir essas relações complexas à etiqueta discursiva "emoção" tem uma vantagem: convida o co-enunciador a ocupar o lugar desterritorizado do sentimento em detrimento do social, do histórico e do cultural. É, portanto, no lugar das relações afetivas, que o co-enunciador será interpelado.

Dessa forma, já a partir de [ $\ 3]$, o enunciador apresenta a emoção como algo incontornável, para o qual haveria necessidade de aprender e dominar "técnicas" de autocontrole. Nessa senda, ele incita o co-enunciador a ocupar, no interior de embreante de pessoa <nós>, o lugar que ele também ocupa, qual seja, o de aluno: "precisamos aprender as ferramentas mais importantes para gerir [a nossas próprias emoções]". Trata-se, agora, de evocar cenas validadas na memória sociocultural a respeito do sentimento de culpa: "Quantas vezes você já se perguntou: Por que eu fui fazer isso?" [ $\mathbb{S 4}$; no sentido de corrigir as trajetórias "emocionais" consideradas desviantes: "Por que não tive autocontrole? Quantas vezes eu magoei pessoas que me são tão caras? Quantas vezes eu repeti erros que já tinha jurado que não ia mais cometê-los? [ $\$ 4]$. Nesse ponto, a enunciação terapêutico-midiática apaga as condições sociais que, porventura, levariam o sujeito a pragmáticas desviantes "moralmente", isto é, magoar, repetir o erro etc.

Nesse cenário introspectivo, as técnicas neoliberais de autocontrole são suscitadas pelo enunciador [ $\mathbb{\$} 5]$. É evidente que o efeito de sentido de mal-estar se faz presente no discurso do texto [1], mas já não se trata de um mal-estar social, de um pessimismo perante a vida em sociedade, como vimos nos discursos em [A] [B] [C] e [D]. O "tom" de pessimismo no discurso do texto [1] tem um estatuto intimista, já que a reflexão se volta para o campo das emoções. Com efeito, o enunciador procura apagar os aspectos morais de uma cultura a fim de introjetar o sujeito no centro do diagnóstico, ou seja, é o eu a causa da enfermidade de si mesmo.

O co-enunciador, então, é enlaçado numa cenografia de ingerência da própria vida afetiva, que o torna, de certa forma, mais vulnerável, a ponto de se recolher em si. Mas a noção de culpa é construída "fora do $e u$ ", paradoxalmente, o 
$e u$ é posto em relação ao cultural. O sujeito se sente culpado por ter tido amizade mais com os outros do que consigo mesmo; ter tido um romance com outros e não "com a sua própria história, com a sua saúde emocional, com a sua liberdade, criatividade e capacidade de gerir a sua emoção" [\$5]. Sem dúvida, uma fetichização de si mesmo; a tentação de Narciso.

$\mathrm{Na}$ verdade, o enunciador invoca o cultural para jogar com a noção de liberdade. As pessoas que não sabem gerir suas próprias emoções "poderão ser escravas vivendo em sociedades democráticas". É o que nos informa o discurso científico etnocêntrico de Nemo (2006) quando este autor ressalta que uma das condições de integralização de uma dada sociedade ao Ocidente seria a promoção da democracia liberal.

De toda forma, jogar com a liberdade democrática num momento em que a democracia se vê ameaçada em diversos países produz um apagamento da própria noção de democracia, ao mesmo tempo em que produz um elã discursivo revelador de liberdade social. Ou seja, se vivemos em uma sociedade democrática, cujas liberdades individuais são garantidas, a solução para o sofrimento estaria em nós, basta sabermos "gerenciar" as nossas emoções.

É evidente que não queremos reduzir os transtornos mentais à questão cultural, tampouco delimitar uma geografia mais ou menos favorável ao sofrimento psíquico. Aqui, apenas, indagamos o jogo com a democracia política, dado que a enunciação terapêutico-midiática invoca um mal-estar social, recuperando considerações do discurso científico e, paradoxalmente, sugere que a democracia nas sociedades ocidentalizadas é plena. De fato, o discurso científico, mesmo com tinta etnocêntrica, não afirma que a América Latina, por exemplo, é plenamente democrática (Cf. NEMO, 2006). E, mesmo em lugares cuja democracia é mais consistente, restaria saber se as pessoas "que sabem gerir suas próprias emoções" são, efetivamente, livres.

"Muitas vezes, não temos problemas no teatro social - fora de nós - mas criamos problemas no teatro da nossa mente. Não se preocupe se você sente que em muitos momentos o pior inimigo seu é você mesmo" [\$7]. O enunciador visa, então, a instaurar um sujeito, ao mesmo tempo, realizado socialmente e fracassado cognitivamente. Trata-se, sem dúvida, de um sujeito clivado entre a vida social e a vida afetiva.

Acontece que a construção da subjetividade supõe a intersubjetividade, isto é, os problemas que "criamos no teatro da nossa mente" estão imbricados com o "teatro social”, se assim não o fosse, não viveríamos em sociedades. É o que Bauman (El País, on-line, 2017) afirma quando diz que, na sociedade líquida, os laços humanos se despedaçaram e o espírito de solidariedade enfraqueceu. A separação e o isolamento tomaram, diz ele, "o lugar do diálogo e da cooperação": 
Da família à vizinhança, do local de trabalho à cidade, não há ambiente que permaneça hospitaleiro. Instaura-se uma atmosfera sombria, em que cada um alimenta suspeitas sobre quem está ao seu lado e é, por sua vez, vítima das suspeitas alheias. Nesse clima de desconfiança exagerada, basta pouco para que o outro seja percebido como um potencial inimigo: será considerado culpado até que se prove o contrário (BAUMAN, El País, on-line, 2017)

Assim, no discurso do texto [1], o enunciador reconfigura a sociedade mobilizando o "tom" de pessimismo da Ciência - quanto à mobilidade dos sujeitos mas reinstala esse "tom" no interior do sujeito, no âmago do $e u$. "Por que você não tem autocontrole em alguns momentos? Por que perde a paciência? Por que não gere seus pensamentos? Por que não protege a sua emoção? Por que reage impulsivamente? E por que, muitas vezes, você tem a sensação de que não dirige o seu próprio script?” [\$6].

Passemos à próxima análise.

Texto $[2]^{15}$

[\$1] A primeira ferramenta: como lhe dar com a ansiedade?

[\$2] Ansiedade é o mal do século na minha opinião. A depressão vai atingir cerca de 20 por cento das pessoas, cedo ou tarde, ao longo da sua história, ao passo que a ansiedade, levando em consideração, principalmente, a sindrome do pensamento acelerado, (sic) nós vamos atingir uma quantidade enorme de pessoas. Talvez 60, 70, 80 por cento de crianças, adolescentes e adultos estão com a mente agitada, ansiosa, acordam cansados, sofrem por antecipação, têm dores de cabeça, dores musculares, têm dificuldades de lhe dar com pessoas lentas, inclusive, interrompem seu sono na madrugada e não conseguem dormir mais. Ou, então, estão com déficit de concentração ou déficit de memória.

[\$3] Portanto, lhe dar com ansiedade, principalmente, desacelerando o pensamento, contemplando o belo e protegendo a emoção é vital para termos saúde psíquica numa sociedade altamente estressante.

[\$4] Uma dica importante para que você possa lhe dar com a ansiedade é não sofrer por antecipação e nem ruminar perdas e frustrações.

15 Como gerenciar a ansiedade. Disponível em: <https://www.youtube.com/watch?v=AWOQ5mQ9wZ8>. Acesso em: 12 fev. 2020. 
[\$5] Mas é quase que inacreditável que o ser humano, o bomo sapiens, essa única espécie que pensa e tem consciência que pensa não gerencia adequadamente a construção de pensamentos, não é educado nas universidades, nas escolas de ensino fundamental e médio para ser autor da sua própria história.

[\$56] Por favor, você não deve ruminar perdas e frustrações, bem como mágoas, crises, críticas...e nem deve, também, sofrer por antecipação; nem deve fazer o velório antes do tempo. Mas como desenvolver consciência crítica, gestão dos pensamentos?

[S7] Uma das técnicas, é a técnica do DCD: duvidar de tudo aquilo que nos controla, criticar cada ideia perturbadora e, também, determinar, estrategicamente, se está solto, relaxado, tranquilo. E como você deve fazer essa técnica do DCD? Interiorizando, não expressando palavras, mas gritando no silencio de sua mente.

[S8] Nunca aceite, passivamente, cada ideia perturbadora. Nunca rumine o passado de maneira também ingênua. Você tem que usar o passado para crescer e tem de pensar no futuro para estabelecer metas para que desenvolva um raciocínio brilhante e soluções inteligentes.

[\$59] Mas nunca esquece: duvidar, criticar e determinar estrategicamente é uma ferramenta excelente do eu que você deve fazer todo os dias no silencio da sua mente para dirigir o script da sua história

O "diagnóstico" de uma sociedade "doente" colabora não apenas para dissipar a existência daquilo que é danoso para os indivíduos, mas também para criar um espaço de "cura" terapêutica em que disputam diversas formações discursivas: a religiosa, publicitária, a didática, a mística, a médica, dentre outras. Por isso, o enunciador inicia com uma pergunta desconcertante para quem sofre de ansiedade: "a primeira ferramenta: como lhe dar com a ansiedade?" [\$1]. Não é, de fato, uma "ferramenta", mas amarra o co-enunciador à enunciação.

A partir daí, o enunciador passa a fazer um prognóstico da depressão em relação à ansiedade. "A depressão vai atingir cerca de 20 por cento das pessoas, cedo ou tarde, ao longo da sua história, ao passo que a ansiedade, levando em consideração, principalmente, a síndrome do pensamento acelerado... nós vamos atingir uma quantidade enorme de pessoas” [\$2]. A questão, neste ponto, é delimitar o objeto, já que o termo "depressão" é muito amplo e estigmatizado socialmente, ao passo que o termo "ansiedade" é mais restrito e menos estigmatizado. 
Além de focar no termo "ansiedade" como "o mal do século", o enunciador específica seus sintomas: mente agitada, cansaço, sofrimento por antecipação, dores de cabeça, dores musculares, dificuldades de lhe dar com pessoas lentas, interrupção do sono na madrugada, déficit de concentração ou déficit de memória $[\$ 2]$. Como bem sabemos, esses sintomas podem ter causas muito diversas, por isso, é conveniente lançá-los num lugar em que a heterogeneidade de indivíduos também seja diversa: a internet. Em outras palavras, além de sintomas bastante comuns no ser humano, a enunciação terapêutico-midiática gravita em itens lexicais genéricos, como "emoções”, "sentimentos”, "saúde psíquica”, “sociedade estressante", dentre outros.

No entanto, embora sintomas comuns, as técnicas para superá-los são removidas das mãos dos indivíduos, para serem transformadas, como lembra Rose (Outras Palavras, on-line, 2020), em ferramentas profissionais. Ou, em termos políticos - conforme o enunciador do texto [C] do nosso corpus de apoio - a despropriação das técnicas no sistema capitalista aprofunda ainda mais as cisões sociais, porque, para aqueles que a elas não têm acesso, escapam-lhes a possibilidade do controle.

Por isso, aquilo que o enunciador oferece de concreto é, desconcertantemente, abstrato: "[...] lhe dar com ansiedade [...] desacelerando o pensamento, contemplando o belo e protegendo a emoção é vital [...]" [\$3]. "Uma dica importante para que você possa lhe dar com a ansiedade é não sofrer por antecipação e nem ruminar perdas e frustrações” [\$4]. Portanto, numa sociedade "altamente estressante" em que a ansiedade e a depressão atinge milhões de pessoas, seria preciso seguir algumas prescrições, quais sejam: contemplar o belo, desacelerar o pensamento, não ruminar perdas, frustrações, mágoas, crises e críticas, não sofrer por antecipação; não fazer o velório antes do tempo [\$6].

Nessa perspectiva, é possível conjecturar que as condições de enunciabilidade do discurso motivacional-religioso sugere, entre outras coisas, que os indivíduos se encontram, pelo menos, desmotivados e descrentes, ou mesmo, "despreparados" para enfrentar as exigências da sociedade moderna. "Mas é quase que inacreditável que o ser humano, o bomo sapiens, essa única espécie que pensa e tem consciência que pensa não gerencia adequadamente a construção de pensamentos” [\$5].

Nessa senda, o enunciador convoca, mais uma vez, o co-enunciador "a descer à terra", ou melhor, invoca uma dimensão que se encontrava apagada: a sociedade e suas instituições: [o ser humano] "não é educado nas universidades, nas escolas de ensino fundamental e médio para ser autor da sua própria história”. Nesse ponto, poderíamos fazer a seguinte indagação: se as escolas de educação básica e as universidades educassem o sujeito "a ser autor de sua própria histó- 
ria”, a ansiedade da população diminuiria ou se extinguiria? Conseguiríamos, enfim, gestar nossas emoções?

Por fim, o enunciador revela a sua técnica para o desenvolvimento do pensamento "consciente crítico" e para a gestão dos pensamentos [\$7]. Trata-se da técnica do "DCD: duvidar de tudo aquilo que nos controla, criticar cada ideia perturbadora e, também, determinar, estrategicamente, se está solto, relaxado, tranquilo" [ [7]. Essa técnica consiste em se calar perante o fracasso suposto das instituições de ensino, para ficarmos no exemplo das escolas e universidades. Assim, sugere-se uma interlocução com o eu que, ao invés de expressar palavras, deve gritar "no silencio de sua mente" [\$7]. Nesse quadro, a dúvida cartesiana que dúvida dos sentidos, passa a duvidar da causa do sofrimento: "aquilo que nos controla".

"Nunca aceite..."; "Nunca rumine..."; "Você tem que..."; "tem de pensar..."; "estabelecer metas...”. O enunciador passa, então, às palavras de ordem para ensinar as técnicas neoliberais de prevenção de transtornos emocionais que, de certa forma, jogam contra a Ciência, em particular, contra a Medicina, a Sociologia, a Antropologia e a Educação; apropriando-se do poder psiquiátrico (ROSE, on-line, 2020; BERARDI, 2017, texto [D]). Nesse sentido, o enunciador convoca o co-enunciador para operar uma higienização das perturbações, de modo a desenvolver "um raciocínio brilhante e soluções inteligentes" [ $\$$ 8]. Sem se esquecer, no entanto, que "duvidar, criticar e determinar estrategicamente é uma ferramenta excelente do eu que você deve fazer todo os dias no silencio da sua mente para dirigir o script da sua história” [\$9].

Passemos à última análise.

Texto [3] ${ }^{16}$

[\$1] Infelizmente, brilhantes pensadores com Freud, Jung, Adler, Kant, Hegel, Vigótski... os existencialistas como Sartre, Nietzsche, Merleau-Ponty, Kierkegaard, que foi o pai do existencialismo. Eles brilharam na construção das suas teorias, mas não tiveram oportunidade de estudar, talvez, a última fronteira da Ciência no processo de construção de pensamentos. E, por isso, não desenvolveram técnicas de gestão da emoção para a prevenção de transtornos emocionais.

[\$2] Veja bem. O pensamento ele é formado em milésimo de segundos. Enquanto eu estou falando com você, sem que você perce-

16 Técnicas para combater a ansiedade e controlar seus pensamentos acelerados Disponível em: <https://www.youtube.com/watch?v=_en39F1i4jI>. Acesso em: 12 fev. 2020. 
ba, uma série de fenômenos está atuando para que você compreenda cada verbo que eu conjugo tempo-espacialmente, cada pronome, cada adjetivo. O que indica que essa última fronteira da Ciência, a construção de pensamentos, de fato, é de uma complexidade sem precedentes. Tão grande que se nós a conhecêssemos minimamente, jamais discriminaríamos as pessoas, seja pela cor da pele, pela sexualidade, pela condição socioeconômica, intelectual ou cultural.

[\$3] Existem três tipos de pensamento: o pensamento essencial, é um pensamento inconsciente; o pensamento dialético, que usa o simbolo da língua; e o pensamento anti-dialético, que usa a imagem, o pensamento imaginário.

[S4] Quanto você tem saudade, você o usa os mais complexos dos pensamentos, que é o pensamento anti-dialético. Um computador, a inteligência artificial jamais sentirá saudade. Quando você experimenta a solidão, está próximo e distância das pessoas, isso é obra do pensamento anti-dialético, mesclado com a emoção. $O$ computador jamais sentirá solidão. Quando você se auto pune, quando você se auto cobra, quando você tem necessidade ansiosa de que os outros gravitem na sua órbita, também, doentiamente, isso é uma construção do pensamento anti-dialético.

[\$55] O pensamento dialético ele é mais simples, dotado da necessidade de símbolos, de códigos, por isso nós usamos para ler, para escrever, para debater.

[\$56] Agora o pensamento essencial é a matriz dos pensamentos dialético/simbólicos ou anti-dialético/imaginários. Esse pensamento essencial, que se forma milésimo de segundos antes de você imaginar, por exemplo, o seu filho na sua mente, ter saudade dele, ou seu namorado ou namorada. Ele surge antes que as palavras ganham o palco da sonoridade, do pensamento dialético.

[S7] Portanto o pensamento essencial está na base do inconsciente. E vou lhes dizer: grande parte dos pensamentos essenciais nem chegam a formar pensamentos conscientes, que é o pensamento dialético e o anti-dialético.

[S8] Sabe aquela angústia que nós temos, que você não sabe da onde veio e por que veio? Não chegou a se formar um pensamento dialético, você não compreende, mas o pensamento essencial excitou a emoção e asfixiou o seu prazer de viver. Sabe aquele sentimento de angústia, ou estado depressivo, ou de ansiedade que você tem e não há uma explicação no meio ambiente, é que o pensamento essencial não 
chegou a formar pensamentos dialéticos/simbólicos, nem imaginários/anti-dialéticos, mas chegou a asfixiar o território da sua emoção.

[\$9] Todas as vezes que nós usamos a técnica da mesa redonda do eu, ou mesmo a técnica do silencio proativo, ou seja, o eu se recusa a agredir quem o agrediu, se recusa a reagir pelo fenômeno bateu-levou; você não atua antes da formação do pensamento inconsciente, ou essencial, mas você constrói janelas lights, que faz com que o fenômeno da alto-secagem da memória não apenas lê as janelas traumáticas - que geram aquelas depressão inexplicável, angústia inexplicável, aquele mau-humor que também não tem uma explicação lógica - ele lê que você contemplou o belo, lê que você é um pessoa segura, líder de si mesmo, ele janelas saudáveis ao redor do núcleo das janelas killer; e você neutraliza, portanto, a ação destes pensamentos: um que asfixia e o outro que liberta.

[\$10] Vejam bem: nós estamos falando da última fronteira da Ciência, é um assunto tão complexo que mesmo a nivel de doutorado ainda não se estuda. Eu acredito que, no próximo século, vamos dar mais ênfase a essa última fronteira da Ciência. Mas saibam que você pode e deve usar técnicas de gestão da emoção que pode levá-lo a ser protagonista da sua própria história.

No texto [1] e [2], os atravessamentos entre discursos constituintes são apagados. Não é, propriamente, o discurso científico que, para se afirmar, invoca a todo momento "a ameaça do discurso religioso ou do filosófico" (MAINGUENEAU, 2008, p. 40). Também, o discurso científico não se apresenta de modo a convergir, num campo, os discursos não-constituintes. Os parceiros legítimos da enunciação terapêutico-midiática não são, evidentemente, um grupo restrito de cientistas. Mas, no discurso do texto [3], emerge mais claramente um enunciador que fala na e pela Ciência, e, dessa forma, pode questionar seus pares. Observamos, então, o discurso científico invocando a ameaça de outros discursos constituintes e, também, enfraquecendo o poder da psicologia e da psicanálise. "Infelizmente, brilhantes pensadores com Freud, Jung, Adler, Kant, Hegel, Vigótski... os existencialistas como Sartre, Nietzsche, Merleau-Ponty, Kierkegaard” [\$1].

Ora, invocar a ameaça de outros discursos constituintes significa, aqui, indicar a limitação dos posicionamentos de identidade fortes nesses discursos. De certa forma, significa mostrar que não apenas a leitura do mundo é limitada, mas também o é o gesto teórico. "Eles brilharam na construção das suas teorias, mas não tiveram oportunidade de estudar, talvez, a última fronteira da Ciência no processo de construção de pensamentos [\$1]. Os nomes de autores mobilizados 
evocam, sem dúvida, um archéion, a sede da autoridade, como coloca Maingueneau $(2000 ; 20006 ; 2008)$. Um corpo de enunciadores consagrados é mobilizado para a enunciação a fim de ter expostas às suas faltas, já que, segundo o enunciador, nenhum deles desenvolveu "técnicas de gestão da emoção para a prevenção de transtornos emocionais" [ $\$ 1]$.

Diante dessas "faltas" teóricas, o enunciador vai compondo colagens informativas a respeito da construção dos pensamentos. Mas, diferente do tipo de informação semântica distribuída entre o dado e o novo (KOCH, 2013), a organização da informação textual se distribui entre as proposições científicas e as sequências explicativas (ADAM, 2011) de regime experiencial. O atravessamento do discurso científico no discurso das mídias torna-se, no texto [3], mais claro.

As proposições científicas produzem um efeito de verdade característico do discurso científico: "o pensamento essencial é a matriz dos pensamentos dialético/simbólicos ou anti-dialético/imaginários [\$6]. As sequências explicativas, por sua vez, produzem um efeito de sentido no bojo da competência emocional dos co-enunciadores. Dessa forma, procura-se colar as verdades das proposições científicas com as memórias afetivas dos sentimentos, construindo uma cenografia didática. O discurso midiatizado produz, então, apenas rasuras do discurso científico, dadas às restrições técnicas dos mídiuns digitais.

No entanto, a cenografia didática é dispersa, pois constrói relações frágeis com as sequências explicativas. Vejamos o esquema abaixo, retirado de [\$2]. A parte escura indica as desconexões entre as sequências explicativas.

\begin{tabular}{|l|}
\hline [a] Enquanto eu estou falando com você, [...] uma série de fenômenos está atuando [...]; \\
\hline $\begin{array}{l}\text { [b] } 0 \text { que indica que essa última fronteira da Ciência, a construção de pensamentos, de fato, é de uma } \\
\text { complexidade sem precedentes. }\end{array}$ \\
\hline \\
\hline [c] Tão grande que se nós a conhecêssemos minimamente, jamais discriminaríamos as pessoas [...] \\
\hline
\end{tabular}

Esquema. 1. Elaborado pelo autor

Em [a], o enunciador explica por que o pensamento é formado em segundos. Esse processo, diz ele, indica que o estudo da construção do pensamento é complexo [b]. Essa complexidade "sem precedentes" sugere que, caso conhecêssemos, mesmo minimamente, a construção dos pensamentos, a discriminação social, política, cognitiva, étnico-racial entre as pessoas não existiria [c]. Por isso que “estamos falando da última fronteira da Ciência, é um assunto tão complexo que 
mesmo a nível de doutorado ainda não se estuda” [\$10].

Nesse momento, a enunciação terapêutico-midiática passa a se legitimar no discurso da Ciência recorrendo às suas conceitualizações teóricas: "Existem três tipos de pensamento: o pensamento essencial [...]; o pensamento dialético [...]; e o pensamento anti-dialético [...] [ $\$ 33]$. Na sequência, recorre-se novamente às sequências explicativas $[\$ 4]$, depois, às conceitualizações teórica [\$5], [\$6] e [\$7], até fundir os sintomas pelo embreante de pessoa <nós>, manuseando textualmente as memórias afetivas e as conclusões científicas. Vejamos:

\begin{tabular}{|l|l|}
\hline Memórias afetivas & $\begin{array}{l}\text { Sabe aquela angústia que nós temos, que você não sabe da onde veio e } \\
\text { por que veio?" [\$8]. }\end{array}$ \\
\hline Conclusão científica & $\begin{array}{l}\text { Então } \\
{\left[\begin{array}{l}\text { [..] Não chegou a se formar um pensamento dialético, você não compreen- } \\
\text { de, mas o pensamento essencial excitou a emoção e asfixiou o seu prazer } \\
\text { de viver [\$8]. }\end{array}\right.}\end{array}$ \\
\hline Memórias afetivas & $\begin{array}{l}\text { Sabe aquele sentimento de angústia, ou estado depressivo, ou de ansieda- } \\
\text { de que você tem e não há uma explicação no meio ambiente? }\end{array}$ \\
\hline Conclusão científica & $\begin{array}{l}\text { E...] é que o pensamento essencial não chegou a formar pensamentos } \\
\text { dialéticos/simbólicos, nem imaginários/anti-dialéticos, mas chegou a } \\
\text { asfixiar o território da sua emoção. }\end{array}$ \\
\hline
\end{tabular}

Esquema 2. Elaborado pelo autor

Nesse sentido, as sequências explicativas de regime experiencial dos sujeitos funcionam como argumentos para a conclusão científica. Porém, as restrições de tempo e espaço nos mídiuns digitais são bastante fortes. Não é possível, muitas vezes, enunciar, nos mídiuns digitais, sem recorrer a uma hipertrofia semiótica e, em particular, sem enunciar por "meias-palavras", materializando rasuras discursivas. Nesse movimento, o enunciador apresenta mais uma técnica neoliberal de gestão da emoção para a prevenção de transtornos emocionais. Trata-se, agora, da "técnica da mesa redonda do eu".

A sociedade e suas configurações política, sociais, econômicas, históricas, entre outras, são apagadas. Como enfatiza o enunciador, "não há uma explicação no meio ambiente" [ $\mathbb{\$} 8$ ]. Até por que a sociedade democrática [texto 1] é posta como uma santa no altar. Nesse quadro, um ethos que recupera caracterizações sócio-psicológicas estereotipadas emerge no discurso, assim, emerge o ethos do sujeito introspectivo, que usa a "técnica do silencio proativo". Nesse interim, o 
enunciador retoma o discurso bíblico proferido por Jesus "Eu, porém, vos digo: não resistais ao perverso; mas, a qualquer que te ferir na face direita, volta-lhe também a outra (Mateus 5:39) "o eu se recusa a agredir quem o agrediu, se recusa a reagir pelo fenômeno bateu-levou" [ $\$ 9$ ].

Por fim, o enunciador inscreve o co-enunciador no interior do processo da construção do pensamento, mesmo afirmando que tal processo ainda não foi plenamente estudado. "Eu acredito que, no próximo século, vamos dar mais ênfase a essa última fronteira da Ciência”.

[S9] [...]você não atua antes da formação do pensamento inconsciente, ou essencial, mas você constrói janelas lights, que faz com que o fenômeno da alto-secagem da memória não apenas lê as janelas traumáticas - que geram aquelas depressão inexplicável, angústia inexplicável, aquele mau-humor que também não tem uma explicação lógica - ele lê que você contemplou o belo, lê que você é um pessoa segura, líder de si mesmo, ele janelas saudáveis ao redor do núcleo das janelas killer; e você neutraliza, portanto, a ação destes pensamentos: um que asfixia e outro que liberta.

Embora os pensadores citados tenham sido brilhantes "na construção das suas teorias [...], não desenvolveram técnicas de gestão da emoção para a prevenção de transtornos emocionais [\$1]. De qualquer modo, o co-enunciador tem, agora, "em suas mãos" as técnicas de gestão da emoção que podem e devem ser usadas, levando-o "a ser protagonista da sua própria história” [\$1], mesmo que essa história esteja imbricada com a mesma sociedade "estressante" da qual ele faz parte.

\section{CONSIDERAÇÕES FINAIS}

Os discursos constituintes tendem a delimitar o lugar-comum da coletividade, de forma a construir um espaço em que as práticas sociais possam se congestionar. As práticas de terapia no campo das mídias evocam os lugares-comuns, pois neles os enunciadores se inscrevem em cenografias que exigem a coparticipação. No canal digital selecionado por nós, a enunciação terapêutica não se materializa nas "bordas discursivas", como acontece em livros de autoajuda, cultos religiosos, panfletos publicitários que, muitas vezes, deixam-se enunciar por um elã motivacional. Ao contrário. O propósito do canal em questão é oferecer terapia, no sentido de ajuda ao outro. Desse modo, convoca os co-enunciadores a a participar do gênero terapêutico. Trata-se, portanto, de uma correspondência 
entre a prescrição médica alternativa e o discurso terapêutico, os quais recorrem a técnicas, legitimando-se no e pelo discurso científico.

Como efeito, a midiatização da prática terapêutica em relação a transtornos mentais opera no bojo da Ciência e do capitalismo neoliberal, produzindo novas lógicas normativas na sociedade contemporânea ocidentalizada e, paradoxalmente, descartando as lógicas já existentes, quando essas interpelam acerca do social, do político, do cultural etc. Na cenografia terapêutica, o sujeito é incitado a promover uma "nova" gestão dos seus próprios sofrimentos no interior do eu. A terapia pela internet funciona, assim, como um laço co-enunciativo em que o co-enunciador-paciente é pego numa armadilha.

Ele recebe a enunciação por uma conversa espontânea, mas os embreantes de pessoa < você>; <nós> indicam os lugares de fala: "Sabe aquela angústia que nós temos, que você não sabe da onde veio [...]” [\$8]. Ou seja, o médico e o paciente têm, mas apenas o médico sabe. Eis, então, a armadilha: a enunciação terapêutico-midiática visa a fornecer as técnicas neoliberais para a superação dos sofrimentos psicossociais, construindo, dessa maneira, um espaço de cura no bojo do interdiscurso, onde os discursos científico, religioso e filosófico-estoicista se atravessam.

Nesse espaço de "cura" construído discursivamente, é possível identificar, também, os atravessamentos entre o discurso científico e os discursos não-constituintes. $\mathrm{O}$ que chamamos de enunciação terapêutico-midiática reúne diversos outros atravessamentos, como o discurso político, o discurso publicitário, o discurso didático, o discurso místico, mas a sua pretensão é ser um discurso mediador entre as teorias científicas e as práticas psicoterapêuticas. Mesmo que negue, a enunciação terapêutico-midiática evoca para si uma autoridade fundante que é mobilizada alhures: no discurso científico.

Porém, o discurso científico - e essa era nossa hipótese inicial - é tomado convencionalmente. $\mathrm{O}$ enunciador corrobora com a ideia de que paira na sociedade contemporânea um mal-estar social, o qual, em particular, o discurso científico, no campo das ciências humanas e sociais, já identificou. De fato, assumir que a sociedade moderna é "estressante" ou que "está doente", possibilita o enunciador fornecer as técnicas necessárias para a "cura" dos indivíduos inseridos nessa sociedade. $\mathrm{O}$ fato é que as técnicas ignoram as cisões sociais, econômicas, política, culturais das sociedades ocidentalizadas. Por isso, é preciso tomar o mal-estar social como um mal-estar emocional, a fim de fornecer ferramentas necessárias para a gerência do $e u$.

O efeito de mal-estar social pode ser verificado através de um "tom" de pessimismo dos sujeitos frente às dificuldades que se impõem na atual sociedade. Como vimos, esse efeito está presente nos posicionamentos enunciativos de iden- 
tidade fortes no campo científico, mas é cimentado, sempre que convém, por enunciadores que falam, nas mídias, em nome da Ciência. O efeito de mal-estar social, então, é apagado, ficando explicita a ideia de cuidado e gerência de si numa sociedade doente. Por isso, as técnicas neoliberais são oferecidas como panaceia: "Mas saibam que você pode e deve usar técnicas de gestão da emoção que pode levá-lo a ser protagonista da sua própria história" [\$10, texto 3]. A “cura", então, é oferecida apagando os processos que provocam as cisões sociais. As técnicas são vendidas, mas não estão, tecnicamente, ao alcance de seus próprios consumidores.

\section{REFERÊNCIAS}

ADAM, Jean-Michel. A linguística Textual: uma introdução à análise textual dos discursos. São Paulo: Cortez, 2011.

BEAUGRANDE, Robert de. New foundations for a science of text and discourse: cognition, communication and freedom of access to knowledge and society. Norwood, New Jersey, Ablex Publishing Corporation, 1997.

BAUDRILLARD, Jean. La société de consummation: ses mythes et ses structures. Préface de J.P. Mayer. Denoël, 1970.

BAUMAN, Zygmunt. A modernidade líquida. Tradução Plínio Dentzien. Rio de Janeiro: Jorge Zahar, 2001.

. As redes sociais são uma armadilha. El País. Entrevista concedida em debate em Burgos, Espanha. 09 jan. 2016. Disponível em:<https://brasil.elpais.com/brasil/2015/12/30/cultura/1451504427_675885.html> Acesso em:14 fev. 2020.

BENVENISTE, Émile. (1970). O aparelho formal da enunciação. In: Problemas de Linguística Geral II. 2. ed. Campinas, SP: Pontes, 2006. p. 81-90.

BERARDI, Franco. Neoliberalismo, assexualidade e desejo de morte. Outras Palavras Disponível em: <https://outraspalavras.net/descolonizacoes/depressao-como-enfrentar-o-fracasso-da-psiquiatria/>. Acesso em: 18 fev. 2020.

BOURDIEU, P. Contrafogos 2. Rio de Janeiro: Jorge Zahar Editor, 1998.

DEBORD, Guy. A sociedade do espetáculo. Tradução Estela dos Santos Abreu. Rio de Janeiro: Contraponto, 1997.

EAGLETON, Terry. The illusions of Posmodernism. Oxford, Inglaterra, 1996.

GIDDENS, Anthony. As consequências da modernidade. Tradução de Raul Fiker. São Paulo: UNESP, 1991.

JAMESON, Fredric. Pós-modernismo e a sociedade do consumo. Tradução Vinicius Dantas Novos Estudos CEBRAP, São Paulo, no 12 pp. jun. 1985.

KOCH, Ingedore Grunfeld Villaça. O texto e a construção dos sentidos. 10 ed. São Paulo: Contexto, 2013.

KUMAR, Krishan. (1995) Da sociedade pós-industrial à pós-moderna: novas teorias 
sobre o mundo contemporâneo. Zahar: Rio de Janeiro, 1997.

LÉVY, Pierre. Cibercultura. Tradução Carlos Irineu da Costa. São Paulo: Ed. 34. 2009.

LIPOVETSKY, Gilles. Os Tempos Hipermodernos. São Paulo: Barcarolla, 2004.

LYOTARD, Jean-François. La condition postmoderne. Rapport sur le savoir. Minuit, 1979.

MAINGUENEAU, Dominique, COSSUTTA, Frédéric. L'analyse des discours constituants. In: Langages, 29] année, $n^{\circ} 117,1995$. Les analyses du discours en France. pp. 112-125.

MAINGUENEAU, Dominique. Analisando discursos constituintes. Revista do GELNE, v. 2, n. 1, 2000, pp. 1-12.

. Discurso Literário. Tradução Adail Sobral. São Paulo: Contexto, 2006.

. Cenas da enunciação. Sírio Possenti e Maria Cecília Péres Souza-e-Silva (Orgs.). São Paulo, Parábolas, 2008.

ROSE, Nikolas. Como enfrentar o fracasso da psiquiatria. Outras Palavras. Disponível em: <https://outraspalavras.net/descolonizacoes/depressao-como-enfrentar-o-fracasso-da-psiquiatria/>. Acesso em 12 fev. 2020.

SANTOS, Milton. Por uma outra globalização: do pensamento único à consciência universal. Record, 2000.

VATTIMO, Gianni. A sociedade transparente. Tradução Hossein Shooja e Isabel Santos. Lisboa: Relógio D’Água, 1992. 